\title{
Laparoscopic retroperitoneal approach for urinary tract surgery. Predictive factors of complications and conversion to open surgery
}

\section{Cirugía urológica mediante acceso lumboscópico. Factores predictivos de complicaciones y conversión a cirugía abierta}

\author{
(iD Tania González-León, ${ }^{1}$ iD Yarumi Ochoa-Gibert, ${ }^{2}$ iD Magela Rodríguez-Prieto, ${ }^{2}$ \\ iD Yalaysy Rodríguez-Gómez. ${ }^{3}$
}

Keywords:

Laparoscopy, Nephrectomy,

Postoperative

Complications,

Retroperitoneal Space

Corresponding author:

*Tania González León.

Centro Nacional de

Cirugía de Mínimo

Acceso, La Habana,

Cuba. Email: tania@

cce.sld.cu

\section{Abstract}

Introduction: Surgery by lumboscopic approach is of choice for some work groups, despite being more arduous and requiring a higher learning curve.

Objective: To assess the lumboscopic approach and identify predictive factors of complications and conversion to open surgery.

Material and Methods: A transversal, retrospective study of 436 patients that underwent surgery by lumboscopy at the National Center for Minimally Invasive Surgery, 2008-2019. Absolute and relative frequencies; the Chi-Square Test and Student's t Test and the Multiple Logistics Regression, were utilized, $(\mathrm{p} \leq 0.05)$.

Results: Renal atrophy due to benign diseases (49.8\%), renoureteral lithiasis (26.6\%), surgery of moderate complexity (71.9\%) prevailed, such as nephrectomy $(50.2 \%) .16 .1 \%$ had undergone prior surgery, and $12.4 \%$ a urinary derivation. $3 \%$ required conversion to open surgery and $18.8 \%$ presented complications. Renal staghorn and non-staghorn lithiasis, surgical technique, level of complexity of the surgery, operative time, transoperative bleeding and length of hospital stay were significantly associated $(p<0.05)$ to complications, but after measuring logistics regression, only hospital stay resulted statistically significant $(\mathrm{p}=0.000)$. Regarding conversion: gender, past history of prior surgery, operative time and bleeding were significantly associated $(\mathrm{p}<0.05)$ in both the univariate and multivariate analysis.

Conclusions: Nephrectomy due to benign causes and surgeries of moderate complexity prevailed in this series. The perioperative outcomes were satisfactory and the most frequent complications were postoperative, infectious and of grade II severity. Longer hospital stay was a predictive factor for complications whereas males, past history of prior surgery, longer operative time and bleeding were identified as predictive factors for conversion to open surgery.

Citation: González-León T., Ochoa-Gibert Y., Rodríguez-Prieto M., Rodríguez-Gómez Y. Laparoscopic retroperitoneal approach for urinary tract surgery. Predictive factors of complications and conversion to open surgery. Rev Mex Urol. 2021;81(6):pp 1-15

${ }^{1}$ Centro Nacional de Cirugía de Mínimo Acceso, La Habana, Cuba

${ }^{2}$ Hospital Pediátrico Docente Cerro, La Habana, Cuba

${ }^{3}$ Hospital Pediátrico Centro Habana, La Habana, Cuba

Received: September 23, 2021

Accepted: November 20, 2021

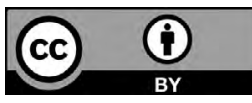




\section{Resumen}

Introducción: La cirugía mediante acceso lumboscópico es electiva para algunos, a pesar de que es más laboriosa y requiere mayor curva de aprendizaje.

Objetivo: Evaluar el abordaje mediante lumboscopia e identificar factores predictivos de complicaciones y conversión a cirugía abierta.

Material y Métodos: Estudio transversal, retrospectivo en 436 pacientes operados mediante lumboscopia, Centro Nacional de Cirugía de Mínimo Acceso, 2008-2019. Se emplearon frecuencias absolutas y relativas; pruebas de Chi cuadrado, t de Student y Regresión Logística Múltiple $(\mathrm{p} \leq 0.05)$.

Resultados: Predominaron atrofia renal por enfermedades benignas (49.8\%), litiasis renoureteral (26.6\%), cirugía de complejidad moderada $(71.9 \%)$ como nefrectomía (50.2\%). 16,1\% tenían cirugía previa y $12,4 \%$ derivación urinaria. El 3\% requirió conversión y el 18,8\% presentaron complicaciones. La litiasis renal coraliforme y no coraliforme, la técnica quirúrgica, el nivel de complejidad de la cirugía, el tiempo quirúrgico, el sangrado transoperatorio y la estancia hospitalaria se asociaron significativamente $(\mathrm{p}<0.05)$ a las complicaciones, después de la regresión logística solo la estancia hospitalaria resultó significativa $(\mathrm{p}=0.000)$. Para la conversión: el sexo, el antecedente de cirugía previa, el tiempo quirúrgico y el sangrado se asociaron significativamente $(\mathrm{p}<0.05)$ en los análisis univariado y multivariado.

Conclusiones: En la serie predominaron la nefrectomía por causas benignas y la cirugía de moderada complejidad. Los resultados perio-

Palabras clave: Laparoscopia, Nefrectomía, Complicaciones Postoperatorias, Espacio Retroperitoneal peratorios fueron satisfactorios y las complicaciones más frecuentes las postoperatorias, infecciosas y de severidad grado II. Mayor estancia hospitalaria constituyó factor predictivo para complicaciones; el sexo masculino, antecedentes de cirugía previa, mayor tiempo quirúrgico y sangrado se identificaron como factores predictivos para conversión a cirugía abierta.

\section{Introduction}

The introduction of laparoscopic surgery in the field of Urology in the 90s of the 20th century, with its numerous advantages, has enabled the development of multiple surgical techniques. Transperitoneal access to the kidney and the urinary tract was the only existing technique until the generalization of the retroperitoneal approach by Gaur, ${ }^{(1)}$ who in 1992, develops the retroperitoneal atraumatic dissection technique with balloon to transform the retroperitoneum into an actual cavity and ensure workspace. This via has been called direct retroperitoneal approach, lumboscopy or retroperitoneoscopy, without distinction. ${ }^{(2-4)}$

This access has advantages: the anatomy is more familiar to urologists; it facilitates direct 
access to the upper urinary tract with less risk of injuring intraperitoneal organs, postoperative paralytic ileus and peritoneal contamination with renal content, besides allowing access to the urinary tract in patients with prior abdominal surgeries. However, the need to transform the retroperitoneum into a cavity gives little workspace and the anatomical references are more difficult, thus increasing the learning curve. This was why the lumboscopic approach was not developed by every work group. Nonetheless, nowadays there are numerous studies that report the outcomes of this approach for the treatment of specific entities and compare them with the transperitoneal approach. ${ }^{(5,6)}$

Performing some of the techniques of the lumboscopic approach is more difficult. Medical literature reports varying percentages of complications and need of conversion to open surgery, in correspondence with the complexity of the techniques included in the different studies. Some report $2.4 \%$ conversion and others $11.7 \%$, while complications are found from $2.4 \%$ up to $19.3 \%{ }^{(7)}$

Urological laparoscopic surgery was initiated in Cuba in 1999, at the National Center for Minimally Invasive Surgery (NCMIS), and in that same year the excision of a renal cyst was performed by lumboscopy. From then on, this work group developed this approach and has widened its range of indications, being the treatment of choice for some surgical entities of the upper urinary tract.

Objective: To assess the outcomes of the lumboscopic approach and identify predictive factors of complications and conversion to open surgery.

\section{Methodology}

A transversal, analytic, retrospective study of a series was carried out with 436 patients who underwent surgery by the lumboscopic approach at the NCMIS between January 2008 and December 2019.

\section{Surgical Technique}

The patient was placed in the lumbotomy position and a small incision, of approximately one $\mathrm{cm}$ penetrating the skin and subcutaneous cellular tissue, was made at a point located one $\mathrm{cm}$ below and in front of the end of the last rib. The aponeurotic muscle planes are opened with Kelly forceps up to the retroperitoneal fat and a small space is created in the retroperitoneum with the index finger to place a dissect balloon which was made by inserting a 12 or 14 Fr Nelaton catheter inside a Penrose drain that was attached to the catheter with 0/1-0 polyester or polyline. The balloon was inserted into the retroperitoneum for at least three minutes and $200-400 \mathrm{ml}$ of $0.9 \%$ saline solution was instilled. Once removed, a $10 \mathrm{~mm}$ trocar was placed and $\mathrm{CO} 2$ was insufflated at $15 \mathrm{~mm} \mathrm{Hg}$ to preserve the workspace, and the incision was sutured for a better adjustment of the trocar to the skin and to avoid gas leak. A 0 or 30 degree optics was introduced within the retroperitoneal space; the peritoneum and the psoas muscle were identified as anatomical references. Under direct vision, two work trocars were placed considering an imaginary lumbotomy incision as reference. Exceptionally, an additional work trocar was required in some procedures. 


\section{Laparoscopic retroperitoneal approach for urinary tract surgery. Predictive factors... Ochoa-Gibert Y., et al.}

\section{Variables}

A database in Microsoft Excel was drawn up to gather the data. The variables studied were age, comorbidities, physical status following the American Society of Anaesthesiologists Physical Status Classification (ASA), surgical diagnosis, past history of prior surgery in the lumbar region and type of prior surgery, presence of urine derivation at the time of surgery, surgical technique performed, complexity following the European Scoring System for Laparoscopic Operations in Urology (ESS), conversion to open surgery, preoperative, postoperative complications and their grade following the Clavien-Dindo Scale.

\section{Information Processing and Analysis}

IBM-SPSS computerized program, version 23.0, was utilized. Measures of central tendency were determined for quantitative variables and absolute and relative frequency for qualitative variables (percentages). Statistical tests were done for the univariate analysis, the Chi-Square Test for qualitative variables and Student's t Test for quantitative variables. The Multiple Logistics Regression with dichotomist response was applied to the variables that presented a significant statistical association. A statistical level of $\mathrm{p}<0.05$ was considered for every test.

\section{Ethical Considerations}

The investigation was approved by the Institutional Review Board (IRB) and the Ethical Review Board (ERB) at the NCMIS. The ethical principles of the declaration of Helsinki for Medical Research with human beings were followed.

\section{Results}

Mean age was 52.1 years (range: $18-83$ years) with a prevalence between 44 and 69 years $(62.6 \%)$. $55.3 \%$ of the patients were female. Most of them had surgery on the left side (51.8\%). $16.1 \%$ had prior surgery upon the lumbar region and percutaneous renal surgery prevailed (11.2\%). 59.4\% of the patients were ASA II and arterial hypertension was the most frequent morbidity (42.7\%). Renal atrophy caused by benign diseases (49.8\%) was the most common diagnosis, followed by lithiasis (26.6\%), prevailing renal non-staghorn (15.8\%). $12.4 \%$ of the patients had urine derivation at the time of surgery and $9.9 \%$ percutaneous nephrostomy. Table1. 
Table 1. Characteristics of the series. Lumboscopic Approach

\begin{tabular}{|c|c|c|}
\hline Variable & Mean & Range \\
\hline \multirow{2}{*}{ Age } & 52.1 & $18-83$ \\
\hline & No. & $\%$ \\
\hline Females & 241 & 55.3 \\
\hline ASA I/II/III & $145 / 259 / 32$ & $33.3 / 59.4 / 7.3$ \\
\hline Left side affected & 226 & 51.8 \\
\hline - Prior lumbar surgery & 70 & 16.1 \\
\hline - Amount of Surgeries: one/more than one & $57 / 13$ & $13.1 / 2.9$ \\
\hline - Percutaneous/URS/ESWL/open/lumboscopy & $49 / 19 / 11 / 1$ & $11.2 / 4.4 / 2.5 / 0.2$ \\
\hline \multicolumn{3}{|l|}{ Surgical diagnosis } \\
\hline - Renal atrophy due to benign diseases & 219 & \\
\hline - Renal and retroperitoneal cyst & 109 & \\
\hline - Renal tumor (parenchyma and urothelium) & 13 & \\
\hline - Pyeloureteral lithiasis & 93 & \\
\hline - Retrocaval ureter & 1 & \\
\hline Urine derivation & 54 & 12.4 \\
\hline
\end{tabular}

Surgery of moderate complexity $(71.8 \%)$ prevailed and in this group, the most frequent procedure was simple nephrectomy for benign diseases (50.2\%). Resection of retroperitoneal cysts was a procedure of low complexity that was performed in $25.2 \%$ of the patients and $3 \%$ were procedures of high complexity. Table 2.

Table 2. Complexity of the surgery. Lumboscopic Approach

\begin{tabular}{|c|c|c|c|c|c|}
\hline Complexity & No. & $\%$ & Surgical Technique & No. & $\%$ \\
\hline \multirow{3}{*}{ Low } & \multirow{3}{*}{110} & \multirow{3}{*}{25,2} & Renal cyst resection & 105 & 24.1 \\
\hline & & & Retroperitoneal cyst resection & 4 & 0.9 \\
\hline & & & Suprarrenal cyst resection & 1 & 0.2 \\
\hline \multirow{4}{*}{ Moderate } & \multirow{4}{*}{313} & \multirow{4}{*}{71,8} & Nephrectomy (benign disease) & 219 & 50.2 \\
\hline & & & Nephrectomy (renal tumor) & 1 & 0.2 \\
\hline & & & Pyelolithotomy & 1 & 0.2 \\
\hline & & & Ureterolithotomy & 92 & 21.1 \\
\hline \multirow{4}{*}{ High/Extreme } & \multirow{4}{*}{13} & \multirow{4}{*}{3} & Ureter anastomosis & 1 & 0.2 \\
\hline & & & Nephroureterectomy & 3 & 0.7 \\
\hline & & & Nephroureterectomy segment & 1 & 0.2 \\
\hline & & & Renal tumor enucleation & 8 & 1.8 \\
\hline Total & 436 & 100 & Total & 436 & 100 \\
\hline
\end{tabular}


Average operative time was 146.1 minutes, $76.8 \%$ of the procedures lasted between 40 and 180 minutes. Mean bleeding was $91.1 \mathrm{ml}$, most (89.4\%) bled $\leq 200 \mathrm{ml}$. The mean length of hospital stay was 2.1 days; in 372 patients (85.3\%) between 1 and 3 days. Conversion to open surgery was necessary in $3 \%$ of the patients. The most frequent cause was severe sclerolipomatosis and $1.8 \%$ were nephrectomies for renal lithiasis. $1.1 \%$ of these patients had prior renal percutaneous surgery. $3.2 \%$ required reintervention, most by minimally invasive surgery. Only two patients $(0.5 \%)$ that presented retroperitoneal abscess needed open surgery. Table 3.

Table 3. Perioperative Outcomes. Lumboscopic Approach

\begin{tabular}{|c|c|c|c|}
\hline Variables & Mean & $S D$ & Range \\
\hline Operative time (minutes) & 146.1 & & $40-780$ \\
\hline Bleeding (ml) & 91.1 & 210.5 & $0-1800$ \\
\hline Length of hospital stay (days) & 2.1 & 3.4 & $1-46$ \\
\hline Variables & No. & & $\%$ \\
\hline Conversion to open surgery & 13 & & 3 \\
\hline - Nephrectomy & 10 & & 2.3 \\
\hline - Ureter-lithotomy & 1 & & 0.2 \\
\hline - Renal tumor enucleation & 1 & & 0.2 \\
\hline Reintervention & 14 & & 3.2 \\
\hline - Open surgery & 2 & & 0.5 \\
\hline - Minimally invasive surgery & 12 & & 2.7 \\
\hline
\end{tabular}

$18.8 \%$ of the operated patients had complications, most postoperatively (17.7\%). The intraoperative complication was bleeding $(1.1 \%)$. Three patients $(0.7 \%)$ required conversion to open surgery to control the bleeding and two $(0.5 \%)$ were resolved during surgery. Four patients were given blood transfusions $(0.9 \%)$. Intraoperative bleeding was associated with nephrectomy for lithiasis in two patients $(0.6 \%)$ and pyeloureteral junction stenosis in one $(0.2 \%)$, nephroureterectomy for urothelial tumor of the tract in another patient $(0.2 \%)$ and renal tumor enucleation in another one $(0.2 \%)$. The most frequent postoperative complications were infectious (14\%), among them port infection (3.7\%). $4.4 \%$ of the patients presented fever and leukocytosis, which was treated with antibiotics thus lengthening hospital stay. $12.4 \%$ postoperative complications were grade II. Two patients underwent percutaneous collection draining (grade IIIb) and $2.8 \%$ were reintervened under general anesthesia (IIIb). $0.5 \%$ was grade IV because they were admitted in the Intensive Care Unit (ICU). No mortality was reported (grade V). Table 4. 
Table 4. Complications. Lumboscopic Approach

\begin{tabular}{|c|c|c|}
\hline Variable & Mean & Range \\
\hline Complications & 82 & 18,8 \\
\hline Transoperative & 5 & 1,1 \\
\hline Postoperative & 77 & 17.7 \\
\hline Infectious & 61 & 14 \\
\hline Retroperitoneal abscess & 4 & 0.9 \\
\hline Ureteral stump abscess & 2 & 0.5 \\
\hline Retroperitoneal collection & 8 & 1.8 \\
\hline Fever & 19 & 4.4 \\
\hline Port infection & 16 & 3.7 \\
\hline Urinary infection & 8 & 1,8 \\
\hline Others & 4 & 0.9 \\
\hline Non-infectious & 16 & 3.7 \\
\hline Retroperitoneal hematoma & 3 & 0.7 \\
\hline Prolonged urinary leakage & 4 & 0.9 \\
\hline Pleural effusion and pneumothorax & 3 & 0.7 \\
\hline Deep venous thrombosis & 3 & 0.7 \\
\hline Others & 3 & 0.7 \\
\hline \multicolumn{3}{|l|}{ Clavien-Dindo Grade } \\
\hline $\mathrm{I}$ & 7 & 1.6 \\
\hline II & 54 & 12.4 \\
\hline IIIa & 2 & 0.5 \\
\hline IIIb & 12 & 2.8 \\
\hline IV & 2 & 0.5 \\
\hline Subtotal & 77 & 17.7 \\
\hline
\end{tabular}

Univariate analysis showed that the presence of renal staghorn lithiasis $(\mathrm{p}=0.000)$ and not non-staghorn ( $p=0.013)$, surgical technique ( $p=0.008)$, level of complexity of the surgery $(p=0.000)$, operative time $(\mathrm{p}=0.027)$, transoperative bleeding $(\mathrm{p}=0.002)$ and length of hospital stay $(\mathrm{p}=0.000)$ were significantly associated with the occurrence of complications, the reason why these variables were considered in the posterior multivariate analysis. Regarding conversion to open surgery, it was found that gender $(p=0.018)$, past history of prior surgery $(p=0.029)$, operative time $(p=0.000)$ and bleeding $(\mathrm{p}=0.000)$ were associated with significance and were taken into consideration in the multivariate analysis. Table 5. 
Table 5. Univariate analysis to relate variables to complications and conversion. Lumboscopic Approach

\begin{tabular}{|c|c|c|c|c|}
\hline \multirow{2}{*}{ Variables } & \multicolumn{2}{|c|}{ Complications } & \multicolumn{2}{|c|}{ Conversion } \\
\hline & $\left(X^{2}\right)$ & p & $\left(X^{2}\right)$ & p \\
\hline Gender & 3.736 & 0.053 & 5.619 & 0.018 \\
\hline Diabetes Mellitus & 0.566 & 0.52 & 2.741 & 0.098 \\
\hline Renal staghorn lithiasis & 13.039 & 0.00 & 0.644 & 0.422 \\
\hline Renal non-staghorn lithiasis & 6.193 & 0.013 & 1.412 & 0.235 \\
\hline Ureteral lithiasis & 0.497 & 0.481 & 0.347 & 0.556 \\
\hline Obesity & 2.406 & 0.121 & 0.315 & 0.575 \\
\hline Prior surgery & 0.413 & 0.521 & 4.761 & 0.029 \\
\hline Urine derivation & 3.055 & 0.080 & 1.412 & 0.235 \\
\hline Type of urine derivation & 5.486 & 0.139 & 2.885 & 0.410 \\
\hline Surgical diagnosis & 15.449 & 0.117 & 18.271 & 0.051 \\
\hline Affected side & 0.233 & 0.629 & 0.022 & 0.883 \\
\hline Surgical risk criterion & 1.864 & 0.394 & 4.507 & 0.105 \\
\hline Surgical technique & 22.277 & 0.008 & 10.310 & 0.326 \\
\hline Level of complexity of the surgery & 16.080 & 0.000 & 5.164 & 0.076 \\
\hline \multicolumn{5}{|c|}{ Student's t Test } \\
\hline Age & 1.599 & 0.809 & 4.704 & 0.319 \\
\hline Operative time & 10.946 & 0.027 & 22.921 & 0.000 \\
\hline Bleeding & 20.956 & 0.002 & 93.731 & 0.000 \\
\hline Length of hospital stay & 34.153 & 0.000 & - & - \\
\hline
\end{tabular}

Following multivariate analysis, the length of hospital stay was the only variable that can be considered a predictive factor of complications in the lumboscopic approach $(\mathrm{p}=0.000)$. Males ( $\mathrm{p}=0.008)$, past history of prior surgery $(\mathrm{p}=0.020)$, operative time $(\mathrm{p}=0.039)$ and bleeding $(\mathrm{p}=0.000)$ were predictive factors for the conversion of lumboscopic surgery to open surgery. Table 6.

Table 6. Multivariate analysis to relate variables to complications and conversion. Lumboscopic Approach

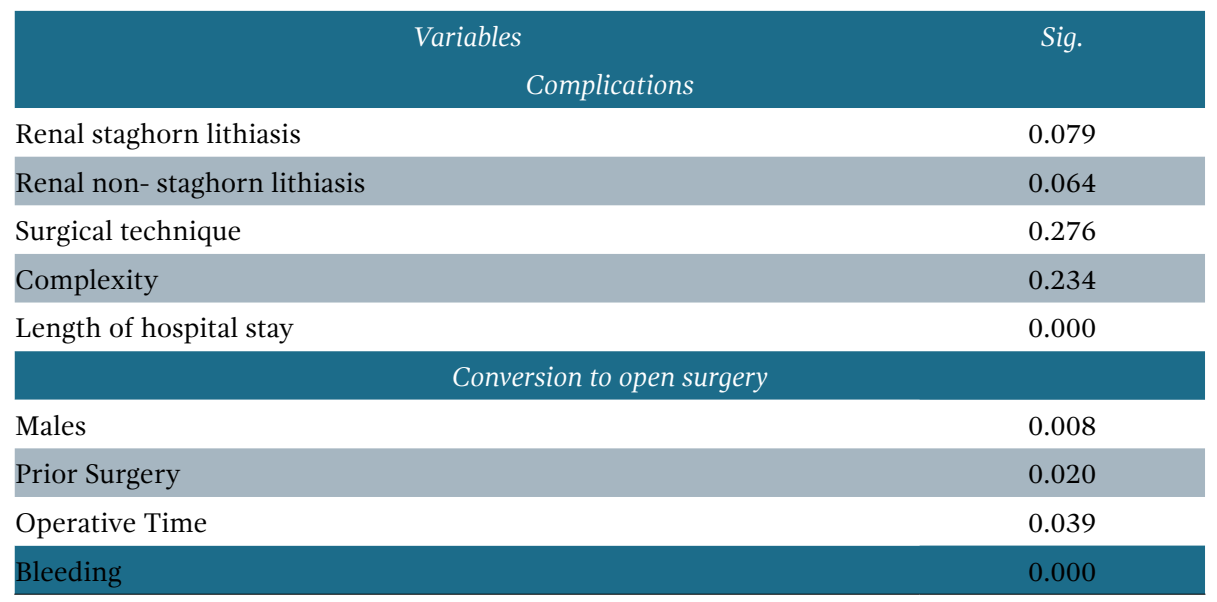




\section{Discussion}

The choice of how to approach the urinary tract, whether by laparoscopy or lumboscopy, depends on the choice of the surgeon and the skills he has achieved. Retroperitoneoscopy is considered a technically challenging approach and not all laparoscopic surgeons are trained for performing this procedure, which limits its utilization. Comparative studies with the transperitoneal approach report that it is less painful and morbidity is lower. In general, this approach is recommended in obese patients or with prior abdominal surgeries. ${ }^{(8)}$

The lumboscopic approach of the urinary tract has been utilized at the NCMIS since the first laparoscopic procedures were introduced in 1999. It is performed, preferably, in those procedures that entail the opening of renal cavities and thus the potential risk of contamination with urine. It is considered of choice for nephrectomy due to benign causes, the treatment of urinary lithiasis in very select cases, and the surgery for renal or retroperitoneal cysts, which does not exclude its use in renal parenchyma tumors and urothelial tumors of the upper urinary tract, as well as in select cases.

A past history of prior surgery in the region was initially a contraindication for retroperitoneoscopy, but as in this investigation, for other authors this is not currently so. Open surgery causes adhesions of the renal unit and particularly in the vascular pedicle area, the planes are difficult to identify, therefore, creating a retroperitoneal space is complicated. Examining the lumbar fossa is important to predict if it will be more or less difficult to create workspace. This work group is of the opinion that when the lumbotomy scar is very hypertrophic, this leads us to suspect that the retroperitoneal fibrosis will be severe and thus the approach very difficult. However, when performing the lumboscopic approach in adulthood in patients who underwent open surgery during childhood, we have observed that access to the retroperitoneum is easier, the perirenal tissue is laxer and an appropriate workspace can be created..$^{(9,10)}$

Renal percutaneous surgery also causes adhesions from the renal unit to the perirenal, which can extend up to the renal hilum. This is the reason some authors recommend the transperitoneal approach in patients with a past history of this surgery. In this series, among the patients with prior renal surgery, those who had undergone percutaneous renal surgery prevailed. $3 \%$ of the patients had more than one prior ipsilateral surgery; this factor increases the complexity of the lumboscopic approach. In a previous study of this same work group regarding complications in lumboscopic simple nephrectomy, it was reported that $7.14 \%$ of the patients had a past history of more than one prior surgery, but no relation was found with the occurrence of more complications. ${ }^{(10,11)}$

The presence of urinary derivation can add greater complexity to the lumboscopic approach. In the series, a percentage of patients, by no means insignificant, had some kind of derivation (nephrostomy or double $\mathrm{J}$ stent) inserted, which was related to performing nephrectomies, mainly or with lithiasis surgery (ureter lithotomy). In a study written by Galahwat et al. ${ }^{(12)}$ the presence of nephrostomy was considered a predictive factor of complexity for lumboscopic surgery, because of adhesions and the difficulty this entails during the dissection of the perirenal space. 
Srivastava et al. ${ }^{(3)}$ reported their results performing lumboscopic approach for the treatment of several urologic conditions; the diagnosis of renal atrophy also prevailed in their study. Lithiasis was the main diagnosis that led to perform nephrectomies due to benign causes in the present investigation. Other causes of renal atrophy as in other reports were pyeloureteral junction stenosis and iatrogenic lesions of the ureter. $^{(13)}$

Resection of renal cysts and ureter lithotomy were the prevailing techniques in another report from the NCMIS in 2012. These surgeries allowed gaining experience to standardize the fact that nephrectomies due to benign conditions be performed by the lumboscopic approach. The series also included techniques of high/extreme complexity, such as nephroureterectomy, end-to- end anastomosis of the ureter and enucleation of renal tumors, which is associated with the greater experience gained in said approach. Other authors show good results of the retroperitoneal approach in surgeries of moderate and high/extreme complexity such as ureter lithotomy, nephrectomy, nephroureterectomy, pyeloplasty, surgery for retrocaval ureter and tumorectomy; with advantages, mainly in obese patients and/or with a past history of prior abdominal surgeries. ${ }^{(3,6,8,14)}$

Srivastava et al. ${ }^{(3)}$ report an operative time of $141 \pm 26 \mathrm{~min}$, similar to that of the series. Liapis et al. ${ }^{(15)}$ stated operative times of 30-400 min, whereas Rasweiller et al. ${ }^{(4)}$ mentioned 30$360 \mathrm{~min}$. Other authors report more blood loss, mainly related with the greater complexity of the surgical technique. ${ }^{(16)}$

In an initial study of 200 cases, Rassweiler et al. ${ }^{(4)}$ reported $7.5 \%$ conversion to open surgery, Gill et al. ${ }^{(17)} 6.6 \%$, Srivastava et al. ${ }^{(3)} 3.2 \%$, whereas Al-Otabi et al. ${ }^{(18)}$ informed $0.7 \%$.
The most frequent cause of conversion to open surgery was sclerolipomatosis associated to nephrectomy because of renal lithiasis and the history of renal percutaneous surgery. The conversion rate decreases as the learning curve improves. Bleeding, technique difficulties, perinephritic adhesions because of past history of recurrent urinary infection and/or renal lithiasis, past history of prior surgery in the ipsilateral lumbar region, large renal masses, adhesions to the vascular pedicle, loss of the plane with neighboring structures (duodenum, colon, cava vein) and complex anatomical situations, are considered the most frequent causes of conversion to open surgery. ${ }^{(3,18)}$

Conversion to open surgery is not, necessarily, considered a complication, but it does reflect the learning curve of the surgeon. In the study, males, past history of prior surgery, operative time and bleeding turned out to be predictive factors for conversion to open surgery. ${ }^{(4)}$

Complications are more frequent when the learning curve has not been completed and they are directly related with the level of complexity of the surgery to be performed. They are the greatest problem the surgeon faces when performing a laparoscopic procedure.

In investigations of surgery performed by the lumboscopic approach, Liapis et al. ${ }^{(15)} \mathrm{stu}-$ died the complications that arose in 600 cases and reported $9.9 \%$, Rassweiler et al. ${ }^{(4)}$ informed $8 \%$ in 200 cases, and Srivastava et al., ${ }^{(3)} 5 \%$.

The most frequent transoperative complications described are hypercapnia, visceral and vascular lesions that can be resolved by means of the same approach, although sometimes can require conversion to open surgery. Some authors describe conversion as the only solution for transoperative accidents related with bleeding, while others have demonstrated that 
laparoscopic treatment is feasible. This is also closely related with the learning curve of the surgeon. ${ }^{(18)}$

Transoperative bleeding in this series represented $5.5 \%$ of the complications, $0.9 \%$ required blood transfusion and $0.5 \%$ needed conversion to open surgery to control the bleeding. Conversion to open surgery as a result of transoperative bleeding in one case was related to nephrectomy for stenosis of the pyeloureteral junction where a lesion of the renal pedicle occurred when the kidney was removed, leading the patient to hypovolemic shock. In another case during nephrectomy for renal lithiasis with severe sclerolipomatosis and adhesions from the kidney to the colon, it was necessary to convert and involve the intentional opening of the colon to complete the surgical procedure. Colostomy was not utilized; primary closure was performed. In one case it occurred during tumorectomy because it was impossible to control the bleeding. All three patients required blood transfusion.

In a multicenter study, Bachar et al. ${ }^{(19)}$ reported that one third of the trans operative complications $(5.2 \%)$ in nephrectomy due to benign diseases, were related with bleeding. Other authors also report that transoperative bleeding is more frequently associated with nephrectomy because of lithiasis and renal tumor, nephroureterectomy and tumorectomy; results that coincide with this study. ${ }^{(18,20)}$

Infectious complications were the most frequent, fever without focalization prevailed which was treated with antibiotic therapy in 17 (3.9\%) patients and two (0.5\%) with general measures. Liapis et al. ${ }^{(15)}$ report 10 patients with hyperthermia without apparent focalization. Infection of the surgical wound refers to one of the surgical ports, generally the site where the specimen was extracted or where the Penrose drain was placed. All cases were treated with antibiotics and the outcome was satisfactory.

Retroperitoneal collection was more frequent in the surgery for lithiasis (ureter lithotomy and nephrectomy) as a result of contamination of the retroperitoneum with renal content. Retroperitoneal hematoma occurred in nephrectomy for renal lithiasis and tumorectomy; they were conservatively resolved with antibiotic therapy. Retroperitoneal abscess was associated with nephrectomy in three patients, two of them for lithiasis. One patient was treated with percutaneous drainage, another with open surgery; the other one only required antibiotic treatment. Liapis et al. ${ }^{(15)}$ report two retroperitoneal abscesses drained surgically. It is valid mentioning that these collections are confined to the retroperitoneum and are spontaneously controlled by the space limits. This is one of the advantages offered by the lumboscopic approach.

Intestinal lesions, paralytic ileus and peritonitis are uncommon when performing lumboscopic surgery because it allows direct access to the retroperitoneal organs. They mainly occur in patients with severe adhesions due to past history of prior surgeries, renal lithiasis and/ or recurrent urinary infection. No unnoticed intestinal lesion was reported in this series, as compared to other revised studies. ${ }^{(3,9,15)}$

In this study, grade II complications prevailed, as in other investigations that report a prevalence of minor complications (grade I, II). ${ }^{(3,15,20)}$

Al-Otaibi et al. ${ }^{(18)}$ reported two grade $\mathrm{V}$ $(0.48 \%)$ complications, one as the result of the perforation of the duodenum complicated with septic shock and another due to pulmonary thromboembolism. Sanli et al. ${ }^{(20)}$ confirm five 
deaths $(0.49 \%)$. This complication did not occur in our series.

It has been demonstrated that the rate of complications depends on the degree of difficulty of the surgical procedure, but this difficulty at the same time diminishes as the experience of the surgeons grow. There are investigations that reveal that the rate of complications in the same work group does not increase, even if the complexity of the surgical procedures is greater. ${ }^{(3,20)}$

A history of staghorn and non-staghorn renal lithiasis, surgical technique and its level of complexity, transoperative bleeding, operative time and length of hospital stay were significantly associated to the occurrence of complications. Nevertheless, after the multivariate analysis was made, only length of hospital stay could be considered a predictive factor of complications.

The incidence of renal lithiasic disease has increased worldwide. This has favored urolithiasis being the main cause for nephrectomy due to benign diseases. In view of this condition, a severe inflammatory process appears in the perirenal region. This increases the technical difficulty of the surgical procedure to a higher degree, mainly in the hilum region because of the presence of large adenopathies, fatty infiltration, fibrosis and adhesions to neighboring structures, which can bring about unnoticed lesions. These special features increase the rate of intraoperative and postoperative complications..$^{(9,19,21)}$

Tepeler et al. ${ }^{(22)}$ compared the rate of complications of lumboscopic nephrectomy between patients with renal lithiasis and other benign diseases and reported that it was higher in patients with lithiasis. Zelhof et al. ${ }^{(19)}$ documented that nephrectomy for lithiasis is asso- ciated with a higher frequency of postoperative complications than nephrectomy due to other benign diseases. In 166 lumboscopic nephrectomies, González et al. ${ }^{(10)}$ concluded that staghorn lithiasis is significantly associated with the occurrence of postoperative complications.

The level of complexity of the surgical technique is directly related to the incidence of complications. Fahlenkamp et al. ${ }^{(23)}$ reported $4.4 \%$ rate of complications in 2047 cases, with $63 \%$ of low and moderate complexity surgeries.

In their series prevailing procedures of moderate and high/extreme complexity, Liapis et al. ${ }^{(15)}$ reported $5.3 \%$ of complications. Al-Otaibi et al. ${ }^{(18)}$ in their study of complications in 411 urologic laparoscopic procedures, reported $4.6 \%$ complications in low complexity procedures; $3.4 \%$ in those of moderate complexity and $5.3 \%$ in those of high/extreme complexity, for a total of $13.6 \%$ complications.

The relevant characteristic in this series is that it belongs to an institution with a wide range of experience in the treatment of different urologic entities by laparoscopy and lumboscopy. This can explain the satisfactory outcomes regarding occurrence of complications and their low severity despite having added surgeries of greater complexity with the passing time. The current trend is to concentrate and centralize complex surgeries. Centralization supposes better perioperative outcomes, better possibilities for suitable training, establishing better guidelines and therapeutic policies with the resulting economic and social impact these aspects entail. ${ }^{(24)}$

Operative time should diminish as the surgeon improves the learning curve. This leads to fewer surgical complications and reduces their severity. However, adhesions, bleeding due to vascular lesions and/or the lesion of adjacent 
organs can significantly complicate laparoscopic procedures and consequently, prolong operative time. ${ }^{(22,25)}$

Patients with complications require prolonged hospitalization, which can explain the significant increase of the length of hospital stay with the occurrence of complications, but, at the same time, the longer the stay in a hospital institution, the higher the risk for complications. These outcomes coincide with those of other authors. ${ }^{(15,26)}$

\section{Conclusions}

Nephrectomy due to benign causes and surgery of moderate complexity prevailed in this series. Perioperative outcomes were satisfactory and the most frequent complications were postoperative, infectious and of grade II severity. Longer hospital stay was a predictive factor for complications while males, past history of prior surgery, longer operative time and bleeding were identified as predictive factors for conversion to open surgery.

\section{Funding}

No sponsorship was received to write this article.

\section{Conflict of interest}

The authors declare no conflicts of interest.

\section{References}

1. Gaur DD. Laparoscopic operative retroperitoneoscopy: use of a new device. J Urol. 1992;148(4):1137-9. doi: 10.1016/s00225347(17)36842-8

2. Saifee Y, Nagarajan R, Qadri SJ, Sarmah A, Kumar S, Pal BC, et al. Retroperitoneoscopic nephrectomy for benign nonfunctioning kidneys: Training and outcome. Indian J Urol. 2016;32(4):301-5. doi: 10.4103/09701591.189724

3. Srivastava A, Sureka SK, Vashishtha S, Agarwal S, Ansari MS, Kumar M. Single-centre experience of retroperitoneoscopic approach in urology with tips to overcome the steep learning curve. J Minim Access Surg. 2016;12(2):102-8. doi: 10.4103/0972-9941.178517

4. Rassweiler JJ, Seemann O, Frede T, Henkel TO, Alken P. Retroperitoneoscopy: experience with 200 cases. J Urol. 1998;160(4):1265-9. doi: 10.1016/s0022-5347(01)62512-6

5. González León T. Laparascopic nephrectomy: different techniques and approaches. Curr Urol Rep. 2015;16(2):7. doi: 10.1007/s11934-0140476-4

6. Rassweiler J, Klein J, Goezen AS. Retroperitoneal laparoscopic non-dismembered pyeloplasty for uretero-pelvic junction obstruction due to crossing vessels: A matchedpaired analysis and review of literature. Asian J Urol. 2018;5(3):172-81. doi: 10.1016/j. ajur.2018.03.001

7. Klap J, Butow Z, Champy CM, Masson-Lecomte A, Defontaines J, De la Taille A, et al. 1,000 Retroperitoneoscopic Procedures of the Upper Urinary Tract: Analysis of Complications. UIN. 2019;102(4):406-12. doi: 10.1159/000497038

8. Lombardo R, Martos R, Ribal MJ, Alcaraz A, Tubaro A, De Nunzio C. Retroperitoneoscopy 
in urology: a systematic review. Minerva Urol Nefrol. 2019;71(1):9-16. doi: 10.23736/S03932249.18.03235-6

9. Danilovic A, Ferreira TAC, Maia GV de A, Torricelli FCM, Mazzucchi E, Nahas WC, et al. Predictors of surgical complications of nephrectomy for urolithiasis. Int braz $\mathrm{j}$ urol. 2019;45:100-7. doi: 10.1590/S1677-5538. IBJU.2018.0246

10. González León T, Ortega Vega E, Morera Pérez M, Sánchez Tamaki R, Quintana Rodríguez M. Complicaciones en la nefrectomía mediante abordaje lumboscópico. Revista Cubana de Urología. 2020;9(1):13-23.

11. Aminsharifi A, Goshtasbi B. Laparoscopic Simple Nephrectomy After Previous Ipsilateral Open Versus Percutaneous Renal Surgery. JSLS. 2012;16(4):592-6. doi: 10.4293/108680812X1 3462882737212

12. Gahlawat S, Sood R, Sharma U, Khattar N, Akhtar A, Pandey PK, et al. Can preoperative clinicoradiological parameters predict the difficulty during laparoscopic retroperitoneal simple nephrectomy? - A prospective study. Urol Ann. 2018;10(2):191-7. doi: 10.4103/ UA.UA_141_17

13. Naghiyev R, Imamverdiyev S, Efendiyev E, Şanlı Ö. Laparoscopic transperitoneal and retroperitoneal simple nephrectomy: The impact of etiological factors of the results of surgical treatment. Turk J Urol. 2017;43(3):319-24. doi: 10.5152/tud.2017.21855

14. González León T, Machado Álvarez $\mathbf{M}$, Rodríguez Verde E, Suárez Marcillán ME, Bautista Olivé J. Empleo de la cirugía lumboscópica en pacientes atendidos en el Centro Nacional de Cirugía de Mínimo Acceso. Revista Cubana de Medicina Militar. 2012;41(2):151-9.

15. Liapis D, de la Taille A, Ploussard G, Robert
G, Bastien L, Hoznek A, et al. Analysis of complications from 600 retroperitoneoscopic procedures of the upper urinary tract during the last 10 years. World J Urol. 2008;26(6):523. doi: 10.1007/s00345-008-0319-3

16. Jain S, Jain SK, Kaza RCM, Singh Y. This challenging procedure has successful outcomes: Laparoscopic nephrectomy in inflammatory renal diseases. Urol Ann. 2018;10(1):35-40. doi: 10.4103/UA.UA_9_17

17. Gill IS, Clayman RV, Albala DM, Aso Y, Chiu AW, Das S, et al. Retroperitoneal and pelvic extraperitoneal laparoscopy: an international perspective. Urology. 1998;52(4):566-71. doi: 10.1016/s0090-4295(98)00314-8

18. Al-Otaibi K. Complications of 411 laparoscopic urological procedures: A single surgeon experience. Urol Ann. 2018;10(3):308-12. doi: 10.4103/UA.UA_190_17

19. Zelhof B, McIntyre IG, Fowler SM, NapierHemy RD, Burke DM, Grey BR, et al. Nephrectomy for benign disease in the UK: results from the British Association of Urological Surgeons nephrectomy database. BJU Int. 2016;117(1):138-44. doi: 10.1111/bju.13141

20. Sanli O, Tefik T, Erdem S, Ortac M, Salabas E, Karakus S, et al. Prospective evaluation of complications in laparoscopic urology at a mid-volume institution using standardized criteria: Experience of 1023 cases including learning curve in 9 years. J Minim Access Surg. 2016;12(1):33-40. doi: 10.4103/09729941.158154

21. Angerri O, López JM, Sánchez-Martin F, Millán-Rodriguez F, Rosales A, Villavicencio H. Simple Laparoscopic Nephrectomy in Stone Disease: Not Always Simple. Journal of Endourology. 2016;30(10):1095-8. doi: 10.1089/end.2016.0281

22. Tepeler A, Akman T, Tok A, Kaba M, Binbay M, 
Müslümanoğlu AY, et al. Retroperitoneoscopic nephrectomy for non-functioning kidneys related to renal stone disease. Urol Res. 2012;40(5):559-65. doi: 10.1007/s00240-0120466-2

23. Fahlenkamp D, Rassweiler J, Fornara P, Frede T, Loening SA. Complications of laparoscopic procedures in urology: experience with 2,407 procedures at 4 german centers. Journal of Urology. 1999;162(3 Part 1):765-71. doi: 10.1097/00005392-199909010-00038

24. Hsu RCJ, Salika T, Maw J, Lyratzopoulos G, Gnanapragasam VJ, Armitage JN. Influence of hospital volume on nephrectomy mortality and complications: a systematic review and meta-analysis stratified by surgical type. BMJ
Open. 2017;7(9):e016833. doi: 10.1136/ bmjopen-2017-016833

25. Cadeddu JA, Wolfe JS, Nakada S, Chen R, Shalhav A, Bishoff JT, et al. Complications of laparoscopic procedures after concentrated training in urological laparoscopy. Journal of Urology. 2001 Dec 1;166(6):2109-11. doi: 10.1016/S0022-5347(05)65515-2

26. Fuat Demirel, Fatih Yalçınkaya, Murat Çakan. Assessment of Technical Difficulty and Complications of Urological Laparoscopic Operations According to "European Scoring System"\&58; 228 Cases. Journal of Urological Surgery. 2015 Jan 1;2(2):69-74. doi: 10.4274/ jus.2015.271 